\title{
DESIGN DE RECURSOS EDUCACIONAIS ACESSÍVEIS: PROPRIEDADES E ELEMENTOS DAS NARRATIVAS DIGITAIS
}

\author{
ACCESSIBLE EDUCATIONAL RESOURCES DESIGN: \\ PROPERTIES AND ELEMENTS OF DIGITAL NARRATIVES
}

\author{
Lane Primo ${ }^{1}$, M.Sc. \\ Berenice Gonçalves ${ }^{2}$, D.Sc. \\ Vânia Ulbricht ${ }^{3}$, D.Sc. \\ (1) Universidade Federal de Santa Catarina (UFSC) \\ e-mail:lanepprimo@gmail.com \\ (2) Universidade Federal de Santa Catarina (UFSC) \\ e-mail: bereni.gon@gmail.com \\ (3) Universidade Federal de Santa Catarina (UFSC) \\ e-mail: vrulbricht@gmail.com
}

Design instrucional, avaliação, deficiência.

Este artigo propõe recomendações para o design instrucional de recursos educacionais acessíveis (REAs). Elas foram elaboradas a partir da análise de quatro REAs, utilizando o método Close Reading sob a lente da taxonomia das narrativas digitais de Nora Paul e das propriedades dos ambientes digitais de Murray.

\section{Instructional design, evaluation, disability.}

This paper proposes recommendations to instructional design of accessible educational resources. They were developed from the analysis of the resources using Close Reading technique by lenses of digital narratives taxonomy by Nora Paul and digital environment properties by Murray.

\section{Introdução}

A proliferação das mídias tem ampliado a geração de informação e de conhecimento que são compartilhados pelo mundo, graças aos avanços das Tecnologias da Informação e Comunicação (TICs). Verifica-se, nas últimas décadas, a mudança de um ambiente analógico para um ambiente digital. Muito mais do que representar informações em formato numérico para ser lido e produzido por dispositivos móveis o mundo digital alterou comportamentos, formas de comunicação e de produção. Tais mudanças impactam em diversos setores da sociedade como, por exemplo, a Cultura e a Educação. Com relação a esta última, o 
$16^{\circ}$ Ergodesign - Congresso Internacional de Ergonomia e Usabilidade de Interfaces Humano Tecnológica: Produto, Informações Ambientes Construídos e Transporte

$16^{\circ}$ USIHC - Congresso Internacional de Ergonomia e Usabilidade de Interfaces Humano Computador

CINAHPA | 2017 - Congresso Internacional de Ambientes Hipermídia para Aprendizagem. relatório Horizon Report 2016 apontou a tendência de aumento da aprendizagem híbrida para os próximos anos para a Educação Superior. Tal relatório é fruto de pesquisa colaborativa e discussão de 58 especialistas que avaliaram o impacto das tecnologias emergentes no Ensino Superior pelo mundo [JOHNSON et al., 2016]. Os resultados apontaram seis tendências, desafios e desenvolvimentos em tecnologia para os próximos cinco anos na Educação Superior. Interessante destacar para este trabalho o que há em comum com os resultados da versão 2015, pois indicam que algo precisa ser realizado. Em desafios solucionáveis, isto é, aqueles que são entendidos e sabe-se como resolvê-los, são comuns: (a) aprendizagem híbrida ${ }^{1}$ formal e informal e (b) melhoria da alfabetização digital; em tendências, para curto prazo, continuou o aumento do uso do design da aprendizagem híbrida; e, em tecnologia, permaneceu o Bring Your Own Device (BYOD), leia-se, "traga o seu dispositivo". Vale chamar a atenção que tanto para a aprendizagem híbrida quanto para o uso dos próprios dispositivos pelos estudantes cresce a expectativa de utilização de recursos educacionais, o que demanda um olhar cuidadoso por parte dos designers. Ao se pensar no horizonte de curto e médio prazos (um ano a três anos, atribuído pelo relatório), parece ser pouco tempo para entender e dar conta desses desafios, todos eles relacionados a ambientes digitais.

Outro dado relevante foi demarcado no Censo EAD.BR 2015. Este apresentou o resultado de cinco milhões de matrículas registradas na Educação à Distância (EAD) e também os percentuais de investimentos realizados na produção de conteúdos e de cursos, que variaram de $20 \%$ a $40 \%$ nas modalidades totalmente à distância e semipresenciais. As instituições respondentes afirmaram que continuarão investindo. Vale ressaltar que no ano anterior o número de matrículas foi de 3.8 milhões [ASSOCIAÇÃO BRASILEIRA DE EDUCAÇÃO

\footnotetext{
${ }^{1}$ Aprendizagem híbrida ou Blended learning integra modalidade presencial e à distância (por meio de ferramentas on-line) na experiência de aprendizagem do estudante [JOHNSON et al., 2016].
}

À DISTÂNCIA, 2016]. Tais resultados são significativos e representam a consolidação da EAD. Contudo, apesar do quadro positivo de crescimento, pois significa um maior acesso à Educação, verificou-se por meio de revisão de literatura que ainda há melhorias a serem realizadas para que estudantes com deficiência possam aproveitar-se das tecnologias e dos conteúdos digitais para desenvolver sua aprendizagem [OBREGON; VANZIN; ULBRICHT, 2015; ULBRICHT; VANZIN; VILLAROUCO, 2011].

No Brasil, o censo demográfico realizado pelo Instituto Brasileiro de Geografia e Estatística (IBGE), em 2010, mostra que $23,9 \%$ da população brasileira apresenta algum tipo de deficiência. Esse percentual representa, aproximadamente, 45,2 milhões de pessoas, das quais mais de 35,6 milhões são pessoas com deficiência (PCDs) visual e mais de 9,6 milhões com deficiência auditiva [BRASIL, 2012]. Nesse sentido, a motivação para o estudo dá-se pela observação do potencial que a convergência das mídias pode proporcionar aos estudantes com deficiência para a inclusão na sociedade por meio da Educação e do Trabalho e por considerar que as mídias são partes de sistemas interativos em ambientes digitais e, portanto, precisam ser acessíveis ${ }^{2}$. Diante desse contexto emerge a questão: em que medida os recursos educacionais estão preparados para potencializar a aprendizagem de estudantes com deficiência visual ou deficiência auditiva em ambientes digitais? Essa preocupação quando vista nas etapas de design e no desenvolvimento podem ajudar a ampliar o acesso a tais recursos.

Considerando a tendência de ampliação da aprendizagem híbrida por meio de tecnologias, o crescimento da EAD, os investimentos para a produção de conteúdos e cursos e a necessidade de atender estudantes com deficiência auditiva (DA) e

\footnotetext{
${ }^{2}$ Segundo a NBR-ISO 9241-210:2010, acessibilidade em sistemas interativos trata-se da "usabilidade de um produto, serviço, ambiente ou facilidade por pessoas com a mais ampla gama de capacidades" [ASSOCIAÇÃO BRASILEIRA DE NORMAS TÉCNICAS, 2011, p. 4].
}

Realização:

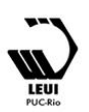




\section{$16^{\circ}$ \\ ERGODESIGN USIHC CINAHPA}

$16^{\circ}$ Ergodesign - Congresso Internacional de Ergonomia e Usabilidade de Interfaces Humano Tecnológica: Produto, Informações Ambientes Construídos e Transporte

$16^{\circ}$ USIHC - Congresso Internacional de Ergonomia e Usabilidade de Interfaces Humano Computador

CINAHPA | 2017 - Congresso Internacional de Ambientes Hipermídia para Aprendizagem. deficiência visual (DV), este artigo adota os referenciais de Paul [2010] e Murray [2011] para identificar características das narrativas e ambientes digitais presentes em recursos educacionais, a fim de discuti-las à luz da acessibilidade. Para tanto, realizou-se uma revisão bibliográfica abordando alguns conceitos relacionados aos ambientes digitais e à acessibilidade para tecer o referencial teórico. $\mathrm{Na}$ sequência, apresentam-se os recursos educacionais acessíveis para, enfim, realizar a análise sob o filtro do referencial teórico. Desta maneira, esperase contribuir para o desenvolvimento de projetos de design de recursos educacionais acessíveis que possam atender às demandas da Educação.

\section{Referencial teórico}

\subsection{Recursos Educacionais e Ambientes Digitais}

A UNESCO define recursos educacionais abertos (REAs) como materiais digitais que são disponibilizados, de forma gratuita e aberta, para o acesso por estudantes e educadores com o propósito de serem utilizados em processos de ensino e aprendizagem. Esses processos podem ser formais, não formais, presenciais e à distância. Os recursos podem ser utilizados na sua forma original ou podem passar por reedição. Por serem abertos e livres, não estão vinculados a cursos específicos, não são tutoriados, nem recebem suporte pedagógico ou técnico [WILSON et al., 2013, p. 192].

Tais recursos educacionais são desenvolvidos e compartilhados em ambientes digitais. $\mathrm{O}$ significado mais geral de ambiente refere-se ao que envolve ou circunda as pessoas e as coisas

[MICHAELIS, 2016]. Nesse sentido, o envolvimento com o mundo digital cresce a partir da década de 1970. Por conseguinte, como parte da evolução, desde os anos 1990 os diferentes tipos de mídias (texto, imagem estática, imagem dinâmica, informações visuais e sonoras, formas e espaços tridimensionais) já dividem o mesmo código digital. Esse código permite que diferentes tipos de mídia sejam mostrados em um computador que atua como dispositivo multimídia de visualização [MANOVICH, 2002, p. 50]. Atualmente, não só a visualização, mas também a manipulação dessas mídias, acontecem no computador e nos diversos dispositivos móveis por meio de programas e aplicativos. De forma natural, as pessoas que usam os dispositivos para produzir, utilizar ou consumir nem sempre percebem, mas estão fazendo parte de ambientes digitais. De acordo com Meyrowitz, citado por Martino [2014, p. 201], é preciso entender as mídias pela metáfora do ambiente, isto é, de que forma elas estão inseridas todo o tempo no dia a dia das relações sociais e também de que modo a vida social articula-se com os meios de comunicação. Lembra que cada meio possui limitações e características que lhe são próprias, assim como possibilita diferentes experiências sensoriais, psicológicas e sociais.

Murray [2011] identifica quatro propriedades dos ambientes digitais: eles são procedimentais, participativos, espaciais e enciclopédicos. A propriedade procedimental está relacionada à execução de regras e algoritmos. Não há a incorporação de comportamentos complexos e aleatórios, mas sim algoritmos e heurísticas que são transformadas em regras e processos; a propriedade participativa é caracterizada pelo diálogo e pela organização participativa; a propriedade espacial relaciona-se à representação de espaços navegáveis. A qualidade espacial é gerada pelo processo interativo da navegação, e possibilita criar a relação de um espaço virtual com outro ao refazer os passos; e, a enciclopédica caracteriza a capacidade de armazenamento e recuperação. Esta visualiza-se nas bibliotecas globais, nas histórias em hipertexto, nos ambientes de jogos de representação on-line, por exemplo. De acordo com a autora, as propriedades procedimentais e participativas podem promover e potencializar a interatividade. Enquanto que as espaciais e enciclopédicas possibilitam a criação de ciberespaços que podem promover e potencializar a imersão. Segundo a autora, as propriedades, seja de forma separada assim como de forma coletiva, são veículos potenciais para a criação literária, o que traz à baila pensar também em narrativas, em especial, as digitais.

\subsection{Narrativas digitais}

As narrativas digitais ganham importância ainda
Realização:
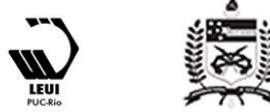


\section{$16^{\circ}$ \\ ERGODESIGN USIHC CINAHPA}

$16^{\circ}$ Ergodesign - Congresso Internacional de Ergonomia e Usabilidade de Interfaces Humano Tecnológica: Produto, Informações Ambientes Construídos e Transporte

$16^{\circ}$ USIHC - Congresso Internacional de Ergonomia e Usabilidade de Interfaces Humano Computador

CINAHPA | 2017 - Congresso Internacional de Ambientes Hipermídia para Aprendizagem. maior na Educação, sendo citadas como "ferramenta pedagógica eficiente e motivadora ao aluno", que agregam valor à pratica docente por inserir a realidade na prática educativa [CARVALHO, 2008, p. 88]. Diante disso, buscouse na literatura referências que pudessem auxiliar a entender como elas - as narrativas - estão relacionadas aos recursos educacionais. Em alguns trabalhos foram encontradas referências à Nora Paul e à taxonomia das narrativas digitais na análise de conteúdos como história em quadrinhos digital, objetos de aprendizagem (OAs), entre outros [BISSOLOTTI; GONÇALVES; PEREIRA, 2015; PRESSER; SANTOS, 2015]. Paul [2010] desenvolveu uma taxonomia para a criação e testagem de narrativas digitais. Ela é composta de cinco elementos: mídia, ação, relacionamento, contexto e comunicação. O elemento mídia (1) está relacionado ao tipo de expressão envolvida na criação do roteiro ou suporte da narrativa, os parâmetros a serem analisados são a configuração que se divide em (M1) conteúdo de mídia individual; conteúdo de mídia múltipla - as mídias estão presentes, mas atuam de forma separada; e, narrativas em multimídia interligados de forma articulada; (M2) o tipo da mídia utilizada; (M3) o fluxo relacionado a sincronicidade (ao vivo, tempo real) ou assincronicidade (gravado, editado); (M4) tempo e espaço verifica o grau de alteração ou edição. O elemento ação (2) está ligado ao movimento do conteúdo e a ação requerida pelo usuário para acesso a esse conteúdo. Os parâmetros são (A1) conteúdo dinâmico; (A2) conteúdo ativo; (A3) combinações entre movimento de conteúdo e ação do usuário. O elemento relacionamento (3) refere-se à relação entre o usuário e o conteúdo, podendo identificar o quanto um conteúdo é fechado ou aberto. Para tanto utiliza os seguintes parâmetros para avaliar o conteúdo que pode ser (R1) linear ou não linear; (R2) padrão ou customizável; (R3) calculável ou não calculável; (R4) fixo ou manipulável; (R5) limitado ou expansível. O elemento contexto (4) relaciona-se ao sentido e as ligações que pode proporcionar. Os parâmetros para análise são: (CT1) narrativa autoexplicativa ou narrativa hipermidiática; (CT2) links paralelos ou links embutidos; (CT3) links internos ou links externos; (CT4) links duplicativos ou links suplementares; (CT5) link contextual, link relacionado ou recomendado. Por fim, o elemento comunicação (5) averigua a habilidade de conexão por meio da mídia digital. Os parâmetros são: (CM1) configuração um a um; um para vários; ou configuração muitos para muitos; (CM2) tipo chat, fórum, e-mail, sms, lista, área de comunicação; (CM3) direcionamento ao vivo ou direcionamento gravado; (CM4) comunicação sem-moderação ou com moderação; (CM5) objetivos de troca de informações, de registro ou de comércio. Os elementos e parâmetros permitem identificar o potencial de interatividade do objeto de análise, como também identificar o impacto das narrativas digitais sobre a audiência.

\subsection{Acessibilidade em ambientes digitais}

Considerando os objetivos do presente estudo, convém abordar sobre acessibilidade. Anjos et al. [2014] explicitam que a acessibilidade está ligada a processos de ergonomia e usabilidade; os autores explicam que esta última busca melhorar a utilização das interfaces pelos usuários, mas a acessibilidade vai além e tem como objetivo atender às necessidades de um público abrangente. A Iniciativa Acessibilidade Web (WAI) da World Wide Web Consortium - W3C [2005], dá o significado para o termo acessibilidade web, explicando que pessoas com deficiências (incluindo os idosos devido à redução de suas capacidades no decorrer do envelhecimento) podem perceber, entender, navegar e interagir com a web, e que podem também contribuir com a web. A WAI disponibiliza diretrizes, como as Recomendações de Acessibilidade de Conteúdo Web (WCAG) 2.0 [WORLD WIDE WEB CONSORTIUM, 2014], baseadas em quatro princípios: perceptível, operável, compreensível e robustez. Segundo a WAI, o cumprimento dessas diretrizes faz com que um conteúdo em ambiente hipermídia (especificamente na web), torne-se acessível para um número maior de pessoas com algum tipo de deficiência, seja surdez e baixa audição, cegueira e baixa visão, incluindo fotossensibilidade e limitações cognitivas, assim como possíveis combinações entre elas. Apesar das recomendações, o que se observa são as dificuldades na interpretação das mesmas. Há trabalhos que buscam soluções para melhorar o 


\section{$16^{\circ}$ \\ ERGODESIGN USIHC CINAHPA}

entendimento, entre elas algumas específicas para objetos de aprendizagem. Macedo [2010] desenvolveu Diretrizes para criação de objetos de aprendizagem acessíveis, elaboradas a partir da convergência de três documentos - Princípios de Design Universal (para conteúdo web) + Recomendações de Acessibilidade para a Criação de Conteúdo On-line (W3C-WCAG 2.0 e W3CWCAG 1.0) + Guia de Desenvolvimento para aplicações de aprendizagem acessíveis (IMS-ACC Guide). O mote é disponibilizar opções alternativas para tornar as mídias (imagens estáticas, imagens em movimento, tabelas, textos, áudios e gráficos), que compõem os objetos de aprendizagem integrantes da experiência, acessíveis a estudantes com deficiência.

\section{Método}

Este estudo é fruto de uma pesquisa básica, que utiliza uma abordagem qualitativa. Ela é exploratória e prescritiva envolvendo o estudo comparativo de quatro recursos educacionais acessíveis utilizando a técnica Close Reading ${ }^{3}$ e revisão bibliográfica. Para análise, optou-se pela lente das características dos ambientes e narrativas digitais de Murray [2011] e Paul [2010] devido à aderência a este tema e ao interesse em aprofundar o assunto. Os passos adotados foram: levantamento bibliográfico do referencial teórico, levantamento das experiências de recursos educacionais acessíveis, elaboração do quadro para identificar os parâmetros de análise, interatividade com os recursos educacionais, análise e resultados.

Os critérios adotados para seleção dos REAs foram: a) ter sido concebido para ser acessível; b) estar disponível para experimentação parcial ou total; e c) possuir informações para consulta por meio de documentação ou artigo publicado.

\section{Na análise dos REAs a técnica de Close Reading}

\footnotetext{
${ }^{3} \mathrm{O}$ Close Reading é uma técnica que percorre o texto entre a microestética e a macroestética. Isto é, busca-se sua explicação ou interpretação cuidadosa (exegese) e a realidade criada pelo autor (diegese). $\mathrm{O}$ resultado estético busca na primeira o suporte da segunda. [WAKI, 2015, p. 21].
}

requer revisitação dos mesmos para identificar os parâmetros e suas relações. Os passos realizados foram: (1) observação dos recursos educacionais cuja interação foi feita três vezes sem qualquer anotação. No caso dos protótipos foram utilizados os arquivos gerados com as indicações e os artigos publicados, uma vez que eles ainda estão em processo de desenvolvimento; (2) nas observações posteriores, procedeu-se ao registro da identificação de pontos que estivessem relacionados às características dos ambientes e narrativas digitais; (3) os registros foram organizados em quadros. A primeira coluna do quadro identifica os critérios e as demais identificam os recursos educacionais e as evidências encontradas; (4) elaboração de gráficos para auxiliar na interpretação do que foi apurado; (5) análise de evidências ou características relacionadas sob a lente do referencial de Murray [2011] e Paul [2010].

\section{Recursos Educacionais Acessíveis selecionados}

Para a análise foram selecionados quatro recursos educacionais que atenderam aos critérios estabelecidos. Dois foram implementados e estão disponibilizados em repositório gratuito para uso e dois são protótipos que estão em fase de testes. Todos são do campo da Matemática, ligados ao grupo de pesquisa Núcleo de Acessibilidade Digital e Tecnologias Assistivas do Programa de Pós-graduação, Mestrado e Doutorado da Engenharia e Gestão do Conhecimento (PPGEGC) da Universidade Federal de Santa Catarina (UFSC) e serão descritos na sequência.

Projeção Cilíndrica Ortogonal em Quadrinhos (PCOQ) é um recurso educacional acessível a surdos no formato história em quadrinhos [BUSARELLO; ULBRICHT; FADEL, 2015]. O mesmo desenvolve narrativa ficcional de forma linear, apresentando o conteúdo e finalizando com uma avaliação. Essa avaliação ocorre depois da narrativa principal e as questões são objetivas no formato múltipla escolha. Ao final, aparece o gabarito com a indicação de erro ou acerto. No caso de erro, o estudante pode refazer a atividade. A história é de Zeca, um rapaz muito tímido, que
Realização:

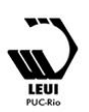




\section{$16^{\circ}$ \\ ERGODESIGN USIHC CINAHPA}

possui admiração por Suzi. Para vencer a timidez ele imagina conversar com Suzi. Ele utiliza os conceitos de Projeção Cilíndrica Ortogonal para projetar a imagem dela e assim treinar sua abordagem. Dessa forma, o conteúdo é desenvolvido. Ao longo do desenrolar da história, há exemplos e conteúdos de aprofundamento que o estudante pode acessar de acordo com a evolução da trama por meio de links (Figura 1). Um mapa com miniaturas dos quadros pode ser utilizada para a navegação. No caso da acessibilidade foram utilizadas informações visuais e verbais para facilitar a apreensão de estudantes surdos e ouvintes e comando para avançar e retroceder pelo teclado.

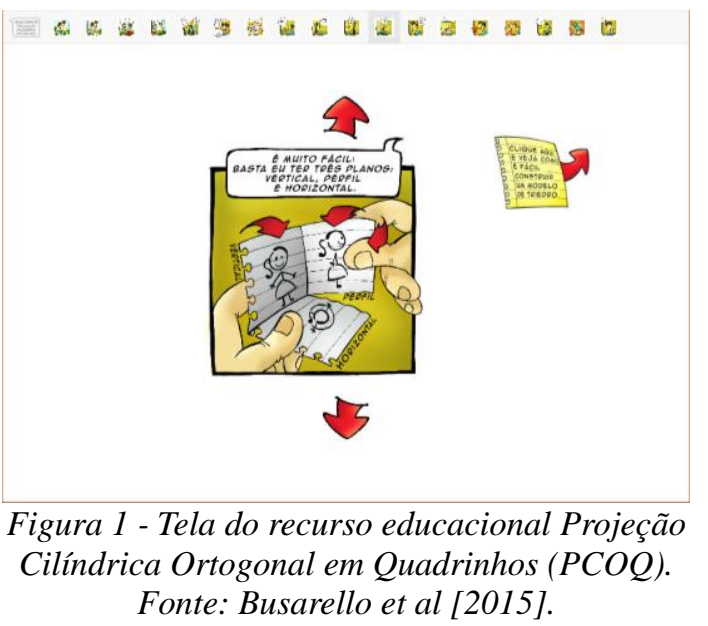

O Enigma de Gaspar é um recurso educacional acessível a surdos para o ensino da Geometria Descritiva, porém no formato de contos [VANZIN; QUEVEDO, 2014]. A narrativa conta a história de Gaspar e como surgiu o conceito de projeção cilíndrica ortogonal, utilizando a metáfora do livro na interface. O estudante pode navegar nas páginas da apresentação de forma sequencial pelo teclado avançando ou retrocedendo, usar as indicações nas laterais ou escolher para onde deseja ir no menu dropdown que aparece do lado direito, Figura 2. No texto há links para os conceitos, exemplos e explicações. Não há exercício ou atividade. Quanto à acessibilidade, as explicações dos conteúdos em texto são acompanhadas de vídeos da interpretação em Libras. Esses vídeos também aparecem nos links dos conceitos e exemplos. $16^{\circ}$ Ergodesign - Congresso Internacional de Ergonomia e Usabilidade de Interfaces Humano Tecnológica: Produto, Informações Ambientes Construídos e Transporte

$16^{\circ}$ USIHC - Congresso Internacional de Ergonomia e Usabilidade de Interfaces Humano Computador

CINAHPA | 2017 - Congresso Internacional de Ambientes Hipermídia para Aprendizagem.

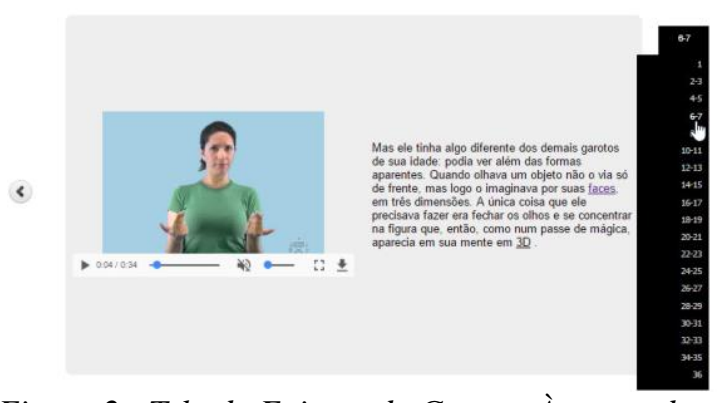

Figura 2 - Tela do Enigma do Gaspar. À esquerda, o vídeo Libras com áudio. À direita, o texto com os links para conceitos. Fonte: Quevedo [2014)

Perímetros é um protótipo de objeto de aprendizagem gamificado e acessível a pessoas com deficiências auditiva e visual para o ensino do cálculo de perímetro de triângulos da Geometria. Segundo os autores, a gamificação foi utilizada como "estratégia de imersão no ambiente virtual, podendo fazer uso de vídeos, animações e ilustrações" [SOMBRIO; SCHIMMELPFENG; ULBRICHT, 2016, p. 2-5). A narrativa é conduzida por um personagem chamado Elvis. O objetivo do uso de um personagem é o de melhorar a interação do estudante com o recurso educacional e com o ambiente virtual de aprendizagem (AVA) [op cit]. O personagem Elvis apresenta o conteúdo e propõe desafios para os estudantes, Figura 3. Na medida em que o estudante avança na navegação, cumpre etapas e resolve os desafios, Elvis comunica a premiação. O estudante também pode utilizar o botão Revisão para voltar ao conteúdo, caso precise tirar uma dúvida ou deseje retomar algum tópico. Os exercícios para a verificação da aprendizagem são acompanhados de mensagens de incentivo. Quando algum erro é cometido, surge uma tela de ajuda para que o estudante possa revisar o conceito relacionado ou receba algum auxílio para a resolução do problema. As características de gamificação utilizadas foram os desafios, feedback, as metas, as regras e a recompensa. Para a acessibilidade, foram estabelecidos requisitos para as mídias texto, imagens estáticas e imagens dinâmicas. O protótipo apresenta características de personalização, possibilita que o estudante escolha as ferramentas que necessita para usufruir da navegação pelo conteúdo. As ferramentas, no formato de barra com botões, são: audiodescrição, vídeo em Libras, alto contraste, tamanho de fonte e legenda. 


\section{$16^{\circ}$ \\ ERGODESIGN USIHC CINAHPA}

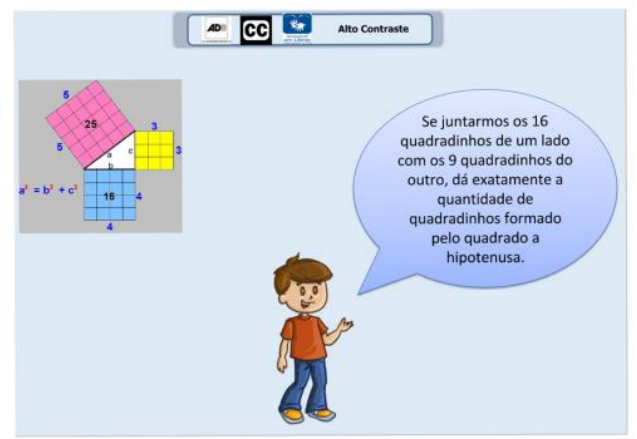

Figura 3 - Tela do Perímetros.

Fonte: Sombrio e Schimmelpfeng [2015].

Poligonópolis é um protótipo de recurso educacional gamificado e acessível a estudantes com deficiências auditiva e visual, composto de objetos de aprendizagem no formato apresentação interativa e atividades gamificadas. Ele foi projetado para trabalhar a unidade temática Polígonos no campo da Geometria para o Ensino Fundamental. Não há personagens. $\mathrm{O}$ estudante interage com o conteúdo da apresentação por meio de uma linguagem dialógica, onde as ações são solicitadas ao longo da exposição. Nas atividades gamificadas, a narrativa desafia o estudante a criar a cidade de Poligonópolis. Para isso, por meio das atividades, ele precisa exercitar o domínio de alguns conteúdos. Ao demonstrar a apropriação, ele recebe uma credencial para assumir os papéis de visitante na fase 1, explorador na fase 2 e empreendedor na fase 3 . Dentre os desafios ele precisa interagir com os colegas para que, juntos, construam a cidade, utilizando somente Polígonos, Figura 4. Ele foi elaborado segundo o modelo ADDIE composto das etapas: Análise, Design, Desenvolvimento, Implementação e Avaliação [FILATRO; CAIRO, 2015]. Segundo Primo et al. [2016], a análise do contexto levou à decisão por um design instrucional misto, no qual uma parte do desenvolvimento é estruturada, isto é, com conteúdos programados e automatizados do modelo fixo e outra parte menos estruturada, que inclui atividades interativas, construção coletiva e links externos configurando, assim, o modelo aberto. Essa escolha foi feita para permitir o uso das TICs, ampliar as possibilidades de interatividade, colaboração e a utilização de ambientes virtuais de aprendizagem (AVAs). No planejamento pedagógico, o conteúdo foi trabalhado na dimensão do conhecimento conceitual e os processos cognitivos lembrar, entender, analisar $16^{\circ}$ Ergodesign - Congresso Internacional de Ergonomia e Usabilidade de Interfaces Humano Tecnológica: Produto, Informações Ambientes Construídos e Transporte

$16^{\circ}$ USIHC - Congresso Internacional de Ergonomia e Usabilidade de Interfaces Humano Computador

CINAHPA | 2017 - Congresso Internacional de Ambientes Hipermídia para Aprendizagem.

e criar utilizando-se a taxonomia de Bloom revisitada [AIRASIAN; MIRANDA, 2002]. Ainda no aspecto educacional, as concepções pedagógicas que apoiaram o desenvolvimento do recurso foram o construtivismo e o sociointeracionismo porque na perspectiva construtivista, o estudante possui o controle sobre a sua aprendizagem mediada pela apresentação interativa de forma autodirigida [BARBERÁ; ROCHERA, 2010]. Segundo eles, por meio dos diferentes formatos da informação (textual, gráfica, sons, imagens estáticas e dinâmicas), $o$ estudante pode adaptar o tempo e esforço cognitivo na construção do conceito proposto pelos objetivos de aprendizagem, atividades e avaliação indicados no planejamento pedagógico. Na perspectiva sociointeracionista, as atividades colaborativas na comunidade (exemplo da Figura 4) podem demonstrar o processo metacognitivo, além do desenvolvimento de atitudes e relacionamentos em um momento histórico.

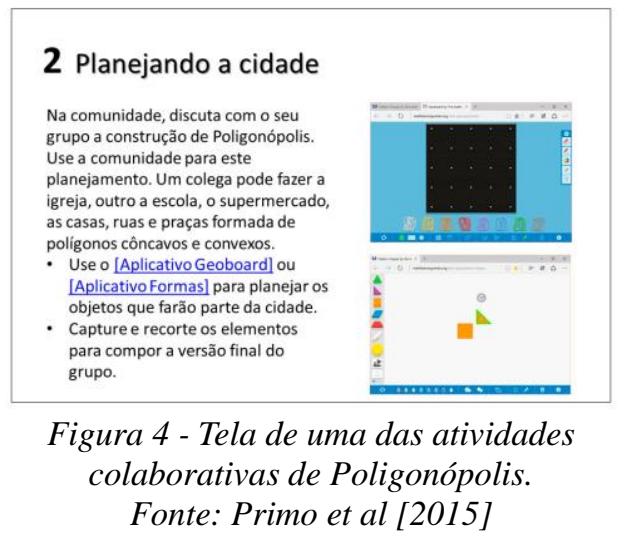

Com relação à acessibilidade, na apresentação interativa foram utilizados para o público com deficiência visual os seguintes recursos: Text alt (informações e breve descrição das imagens e vídeos que são inseridos nas propriedades dessas mídias), ordenação da sequência dos elementos para a identificação dos leitores de tela, inclusão do botão Texto Alternativo, que direciona para uma tela com links para acesso à versões de arquivos para impressão tátil ou Braille e de leitura de texto em voz. Para o público com deficiência auditiva foram incluídos vídeo Libras com legendas e som cujo áudio pode ser aproveitado também pelos estudantes com deficiência visual. Para as atividades gamificadas foi incluído vídeo Libras
Realização:
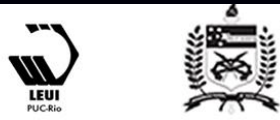


\section{$16^{\circ}$ \\ ERGODESIGN USIHC CINAHPA}

$16^{\circ}$ Ergodesign - Congresso Internacional de Ergonomia e Usabilidade de Interfaces Humano Tecnológica: Produto, Informações Ambientes Construídos e Transporte

$16^{\circ}$ USIHC - Congresso Internacional de Ergonomia e Usabilidade de Interfaces Humano Computador

CINAHPA | 2017 - Congresso Internacional de Ambientes Hipermídia para Aprendizagem. para estudantes com DA e, para os estudantes com DV, áudio, links de arquivos para impressão Braille e formato tátil, Figura 5.

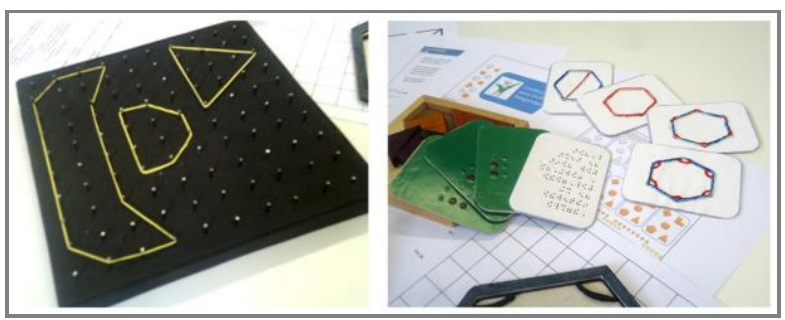

Figura 5 - Exemplos de materiais táteis cujos arquivos estão em Material de Apoio.

Fonte: Primo et al [2015]. Foto: Léo Schimmelpfeng

\section{Resultados}

Os parâmetros identificados nos REAs foram compilados em um quadro, Figura 6, cujos resultados serão apresentados na sequência.

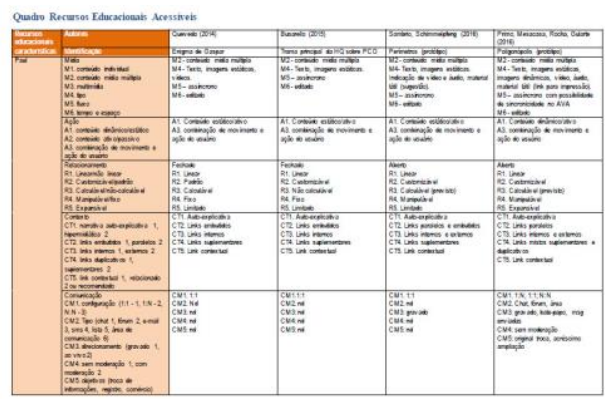

Figura 6 - Compilação dos resultados. Disponivel em: https://goo.gl/wCqDsy. Fonte: Elaboração das autoras.

No aspecto pedagógico, três REAs incluíram exercícios. Em PCOQ e Perímetros eles são de múltipla escolha. Poligonópolis apresentou atividades de associação, caça-palavras e criação coletiva com compartilhamento.

Quanto às mídias, todos os REAs utilizaram texto e imagens estáticas. Vídeos com áudio estavam presentes em três, exceto PCOQ. Áudio e links para material tátil estavam presentes em Perímetros e Poligonópolis. Imagens dinâmicas apareceram somente em Poligonópolis.

Com relação à acessibilidade, os quatro estão preparados para atender a pessoas com deficiência auditiva, sendo que Perímetros e Poligonópolis são acessíveis também a pessoas com deficiência visual. Estes últimos por serem protótipos estão com as indicações para a implementação. Os recursos encontrados ou indicados foram: Libras em três, exceção no REA PCOQ, que trabalhou com imagens estáticas com audiodescrição.

Perímetros e Poligonópolis apresentaram barra de acessibilidade que agregam em comum, botões do tipo liga/desliga para audiodescrição, vídeo Libras, legendas; os dois REAs diferem em alto contraste, presente em Perímetros e link para Texto alternativo em Poligonópolis. No teste, utilizando o leitor de tela NVDA, PCOQ e Poligonópolis, apresentaram melhor desempenho.

Nos parágrafos seguintes serão apresentados os resultados considerando a taxonomia de Nora Paul. Para o elemento mídia, a Figura 7 mostra que os quatro REAs apresentaram suas narrativas utilizando-se uma configuração (M1) de mídia múltipla, isto é, elas estão presentes, porém atuam de forma separada de acordo com a decisão do usuário. Quanto ao tipo (M2) utilizaram um mínimo de duas mídias: texto e imagem estática em PCOQ e seis em Poligonópolis (texto, imagem estática, imagem dinâmica, vídeo, áudio e material tátil). Tanto para o fluxo (M3) quanto tempo e espaço (M4), os quatro recursos educacionais tiveram o mesmo resultado - são assíncronos e houve edição do conteúdo.

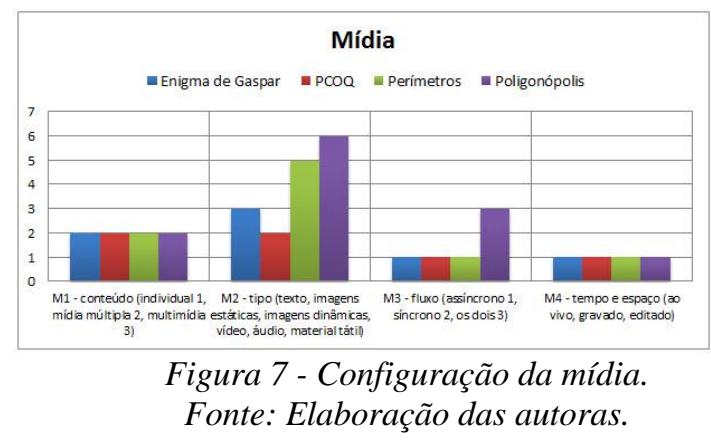

No tocante à ação da narrativa que envolve o movimento do conteúdo e a ação do usuário, três REAs apresentaram conteúdo estático (A1) enquanto Poligonópolis apresentou conteúdo dinâmico em algumas das explicações. Nos quatro, os conteúdos são ativos (A2), isto é, algum movimento é necessário. De igual maneira, houve a combinação do movimento e da ação do usuário (A3) em todos eles.
Realização:
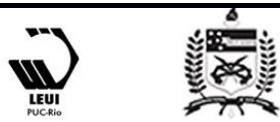


\section{$16^{\circ}$ \\ ERGODESIGN USIHC CINAHPA}

O elemento relacionamento (Figura 8) apresentou como resultado: ordem linear (R1) nos quatro REAs; parâmetro de informações (R2) customizável em três, exceção do Enigma de Gaspar cujo conteúdo é padrão e pouco interfere no interesse do usuário; para as respostas dos usuários (R3), três REAs são considerados calculáveis por registrarem as respostas, mesmo que de forma temporária. A exceção foi mais uma vez Enigma de Gaspar, que não disponibilizou este recurso. Perímetros e Poligonópolis permitem manipulação dos dados (R4), enquanto os outros dois são fixos. Por fim, apenas Poligonópolis permite acrescentar ou guardar contribuições ao conteúdo, sendo considerado expansível (R5) enquanto os demais são limitados nesse quesito.

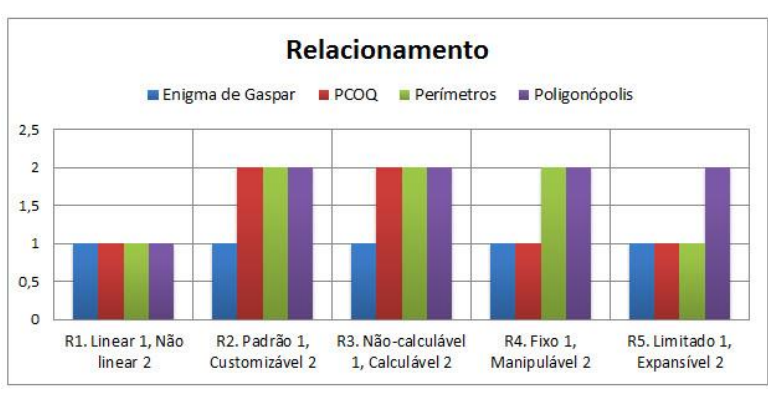

Figura 8 - Relacionamento.

Fonte: Elaboração das autoras.

No elemento contexto, Figura 9, os quatro REAs são considerados autoexplicativos (CT1) e possuem links contextuais (CT5). Perímetros apresentou tanto links embutidos quanto paralelos (CT2). Esse REA, junto com Poligonópolis, apresentaram links internos e externos (CT3).

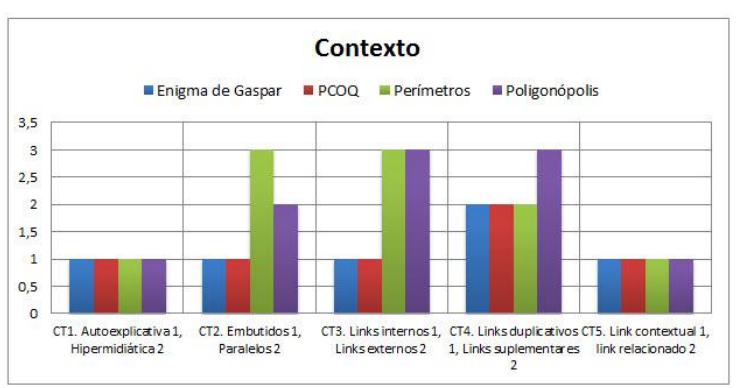

Figura 9 - Contexto. Fonte: Elaboração das autoras.

Quanto ao elemento Comunicação, os REAs foram avaliados nos cinco aspectos, Figura 10.

Poligonópolis foi o que apresentou indicação para todos os aspectos: configuração (CM1), que prevê a $16^{\circ}$ Ergodesign - Congresso Internacional de Ergonomia e Usabilidade de Interfaces Humano Tecnológica: Produto, Informações Ambientes Construídos e Transporte

$16^{\circ}$ USIHC - Congresso Internacional de Ergonomia e Usabilidade de Interfaces Humano Computador

CINAHPA | 2017 - Congresso Internacional de Ambientes Hipermídia para Aprendizagem. conexão de muitos para muitos, três tipos de modos (CM2) de comunicação (chat, fórum e área para publicação), indicação das formas de direcionamento (CM3) - ao vivo, gravado ou mensagens, moderação (CM4) sem supervisão e objetivo (CM5) de troca de informações. Os demais REAs, Perímetros apresentou dois aspectos, Configuração um para um e direcionamento mensagens. Os outros dois restantes apresentaram somente a configuração um para um.

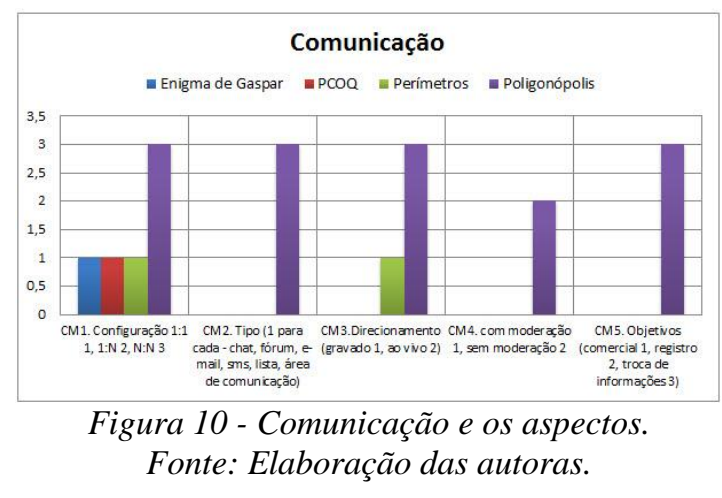

\section{Discussão}

Os resultados da análise dos quatro recursos educacionais acessíveis, segundo a taxonomia das narrativas digitais, mostraram que todos atendem aos parâmetros de forma parcial. Destaca-se que os protótipos apresentam potencialidades, embora precisem de aprimoramentos.

Para essa discussão convém resgatar Meyrowitz, citado por Martino [2014], a fim de buscar interpretar esses dados, considerando como as relações sociais articulam-se com os meios de comunicação e proporcionam diferentes experiências sensoriais, psicológicas e sociais. Nesse sentido, infere-se que quanto mais possibilidades de comunicação maior o potencial de experiências sociais. Diante disso, em escala do menor para o maior, Enigma do Gaspar e PCOQ são os que menos possibilitam experiências sensoriais e sociais enquanto Perímetros e Poligonópolis, além de favorecerem tais experiências em maior escala; por serem protótipos em teste, ainda podem evoluir e melhorar nesse sentido. Portanto, como aprimoramento, sugere-se potencializar os elementos: mídia disponibilizando 


\section{$16^{\circ}$ \\ ERGODESIGN USIHC CINAHPA}

mídia múltipla e multimídia; no elemento ação, proporcionar conteúdos ativos que provoquem a intervenção do estudante; no elemento relacionamento, desenvolver conteúdos abertos que possam ser não-lineares, customizáveis, calculáveis, manipuláveis e expansíveis; no elemento contexto, oportunizar conteúdos adicionais que remetam a outros materiais, caracterizando uma narrativa hipermidiática, com links paralelos, e, na medida do possível, a combinação de links externos, suplementares por um lado e duplicativos por outro, com o fito de atender a acessibiliade; em comunicação, recomenda-se proporcionar trocas de muitos para muitos, por meio de diversos modos (fórum, chat, entre outros). Acredita-se que, dessa forma, é possível favorecer experiências sensoriais que permitam alterar as condições psicológicas dos indivíduos e sua relação com o grupo.

De acordo com Paul [2010], a narrativa digital rompeu o paradigma da narrativa tradicional. A mudança foi a quebra do controle do produtor de conteúdos para uma narrativa em que eles são criados pela colaboração dos usuários. Nessa perspectiva, dos quatro REAs, Poligonópolis é o que apresenta potencialidade para a criação coletiva prevista nas atividades gamificadas.

Outro aspecto a ser considerado é a visão de Murray [2010] no que tange à interatividade decorrente das propriedades procedimentais e participativas e à imersão advinda das propriedades espaciais e enciclopédicas em ambientes digitais. Os quatro REAs propiciam imersão, porém Perímetros e Poligonópolis acentuam o caráter interativo. Esses dois apresentam mais propriedades procedimentais notadamente por causa da gamificação. Por outro lado, a organização participativa é mais acentuada em Poligonópolis.

Por fim, no quesito acessibilidade, pelo fato de pertencerem a um grupo de pesquisa, percebe-se que há evolução. O progresso é evidenciado nos protótipos que apresentam a ampliação de recursos acessíveis para estudantes com DA e com DV. Ao passo que nos dois primeiros, já implementados, o foco está para o atendimento ao público com DA.
Nos protótipos, as barras com botões para as ferramentas acessíveis são fatores positivos que favorecem a escolha por parte do usuário de qual recurso é o mais apropriado para a sua necessidade. Indica, portanto, atenção e respeito pelo público.

Ao comparar o processo de desenvolvimento dos quatro REAs verificou-se que Poligonópolis é fruto de projeto de design instrucional (DI) o que pode ter contribuído para o mesmo estar mais alinhado ao contexto digital.

\section{Considerações sobre o Design instrucional em ambientes digitais}

Ambientes digitais demandam a preparação dos profissionais envolvidos no desenvolvimento de artefatos, sejam eles dispositivos ou conteúdos para recursos educacionais acessíveis. Nesse sentido, diante do crescimento da EAD, que leva ao aumento da produção de conteúdos e cursos, considera-se importante que os projetos de design instrucional estejam alinhados às propriedades dos ambientes digitais, aos elementos das narrativas digitais e às diretrizes de acessibilidade para que os recursos educacionais possam potencializar a aprendizagem de todos os estudantes. Portanto, como contribuição considera-se importante destacar algumas das recomendações a serem inseridas nas etapas Design e Desenvolvimento do modelo ADDIE:

1. Seguir as diretrizes de acessibilidade para as mídias utilizadas, disponibilizando opções alternativas para o conteúdo compatíveis com as tecnologias assistivas (leitores de tela);

2. Utilizar mídia múltipla e multimídia;

3. Planejar utilizando a taxonomia de Bloom revisitada de forma que os conteúdos sejam ativos para trabalhar a ação do estudante, articulando objetivos de aprendizagem, atividades e avaliação nas dimensões de conhecimento e processos cognitivos mais complexos;

4. Incluir parâmetros para o desenvolvimento de conteúdo aberto, não-linear, que possa ser customizado, calculável, manipulável e expansível;

5. Ampliar possibilidades de comunicação, promovendo a conexão de muitos para muitos. 
$16^{\circ}$ Ergodesign - Congresso Internacional de Ergonomia e Usabilidade de Interfaces Humano Tecnológica: Produto, Informações Ambientes Construídos e Transporte

$16^{\circ}$ USIHC - Congresso Internacional de Ergonomia e Usabilidade de Interfaces Humano Computador

CINAHPA | 2017 - Congresso Internacional de Ambientes Hipermídia para Aprendizagem.
Para finalizar, destaca-se a relevância de se avaliar os protótipos por diversos públicos a fim de que os aprimoramentos sejam indicados e possam ser implementados a tempo.

\section{8 À Guisa de Conclusão}

Este trabalho investigou em que medida os REAs estão preparados para potencializar a aprendizagem de estudantes com DV ou DA em ambientes digitais. Para isso, analisou quatro REAs acessíveis, utilizando a taxonomia das narrativas digitais de Nora Paul e as propriedades dos ambientes digitais de Murray. Concluiu que, apesar dos REAs estarem no caminho certo, ainda há melhorias a serem realizadas. Para isso, propôs aprimoramentos para os protótipos.

A título de contribuição elencou recomendações a serem incluídas nos projetos de design instrucional de REAs e cursos, visando prepará-los para o contexto dos ambientes digitais. A limitação deste trabalho está em abordar a acessibilidade no contexto tecnológico. Portanto, para trabalhos futuros, sugere-se ampliar o estudo da acessibilidade em projetos de DI para a dimensão pedagógica articulada às dimensões tecnológicas e comunicacionais que foram parcialmente tratadas neste artigo. Espera-se que este estudo possa auxiliar, de alguma forma, a designers instrucionais e de interação, contribuindo para tornar realidade o aumento do número de estudantes com deficiência, visando a inclusão na sociedade por meio da Educação e do Trabalho.

\section{Referências}

ASSOCIAÇÃO BRASILEIRA DE EDUCAÇÃO À DISTÂNCIA. Censo EAD.BR: Relatório Analítico da Aprendizagem à Distância no Brasil 2015.

Curitiba: Ibpex, 2016.

AIRASIAN, P. W.; MIRANDA, H. The Role of Assessment in the Revised Taxonomy. In: Theory into Practice. Ohio: College of Education. The Ohio State University, v. 41. n.4, 2002. p. 249-254.

ANJOS, T. P. D. et al. Usabilidade e Acessibilidade de Moodle: Recomendações para o Uso do Ambiente
Virtual de Ensino e Aprendizagem pelo Público Idoso. In: Human Factors In Design. Florianópolis: [s.n.], v. 5, 2014. Cap. 3, p. 1-20.

\section{ASSOCIAÇÃO BRASILEIRA DE NORMAS} TÉCNICAS. NBR 9241: Ergonomia da interação humano-sistema - Parte 210: Projeto centrado no ser humano para sistemas interativos. Rio de Janeiro: ABNT, 2011.

BARBERÁ, E.; ROCHERA, M. J. Os ambientes virtuais de aprendizagem baseados no projeto de materiais autossuficientes e na aprendizagem autodirigida. In: CÉSAR COLL, C. M. O. Psicologia da Educação Virtual: aprender e ensinar com as tecnologias da informação e comunicação. Porto Alegre: Artmed, 2010. Cap. 7, p. 161.

BISSOLOTTI, K.; GONÇALVES, B. S.; PEREIRA, A. T. C. Hiperlivro: análise das narrativas digitais de criação e edição on-line de hipermídia educacional.

$7^{\circ}$ Conahpa - Congresso Nacional de Ambientes Hipermídia para a Aprendizagem. Hipermída e Interdisciplinaridade na geração de conhecimento.São Luís, MA. São Paulo: Pimenta Cultural. 2015. p. 1-13.

\section{BRASIL. SECRETARIA DE DIREITOS} HUMANOS DA PRESIDÊNCIA DA REPÚBLICA (SDH/PR). Secretaria Nacional de Promoção dos Direitos da Pessoa Com Deficiência (Snpd). Cartilha do Censo 2010 - Pessoas com Deficiência. Luiza Maria Borges Oliveira. Coordenação-Geral do Sistema de Informações sobre a PCD, 2012.

BUSARELLO, R. I. Geração de conhecimento para usuário surdo baseada em histórias em quadrinhos hipermidiáticas. Dissertação. Florianópolis: UFSC, 2011.

\section{R. I.; ULBRICHT, V. R.; FADEL, L. M.}

Comparando a estrutura de objetos de aprendizagem em histórias em quadrinhos hipermídia. X Conferência Latino-Americana de Objetos e Tecnologias de Aprendizagem. Maceió, AL: CBIE-LACLO 2015. 2015. p. 158-167.

\section{CARVALHO, G. S. As Histórias Digitais:}

Narrativas no Século XXI. O Software MovieMaker como Recurso Procedimental para a Construção de Narrações. Dissertação. São Paulo: USP, 2008. 


\section{$16^{\circ}$ \\ ERGODESIGN USIHC CINAHPA}

$16^{\circ}$ Ergodesign - Congresso Internacional de Ergonomia e Usabilidade de Interfaces Humano Tecnológica: Produto, Informações Ambientes Construídos e Transporte

$16^{\circ}$ USIHC - Congresso Internacional de Ergonomia e Usabilidade de Interfaces Humano Computador

CINAHPA | 2017 - Congresso Internacional de Ambientes Hipermídia para Aprendizagem.
FILATRO, A.; CAIRO, S. Produção de conteúdos educacionais. São Paulo: Saraiva, 2015.

JOHNSON, L. et al. NMC Horizon Report: 2016 Higher Education Edition. Austin, Texas.: The Media Consortium, 2016.

MACEDO, C. M. S. Diretrizes para criação de objetos de aprendizagem acessíveis.Tese. Florianópolis: UFSC, 2010. Disponivel em: <https://goo.gl/PTccnw >. Acesso em: 10 fev. 2017.

\section{MANOVICH, L. The Language of New Media.}

London: The MIT Press, 2002.

MARTINO, L. M. S. Teoria das Mídias Digitais: linguagens, ambientes, redes. Petrópolis, Rio de Janeiro: Vozes, 2014.

MICHAELIS. Moderno Dicionário da Língua Portuguesa, 2016.

MURRAY, J. Affordances of the medium. In: MURRAY, J. Inventing the Medium Principles of Interaction Design as a Cultural Practice. Cambridge: MIT Press, 2011. p. 56-92.

OBREGON, R. F. A.; VANZIN, T.; ULBRICHT, V. R. AVA inclusivo: recomendações para design instrucional na perspectiva da alteridade. São Paulo: Pimenta Cultural, 2015, 234 p.

PAUL, N. Elementos das narrativas digitais. In: FERRARI, P. Hipertexto e Hipermídia: as novas ferramentas da comunicação digital. São Paulo: Contexto, 2010. p. 121-139.

PRESSER, A. T. D. R.; SANTOS, B. G. Framed: a narrativa das histórias em quadrinhos em ambiente hipermidiático. Tríades - Transversalidade, Design e Linguagens, Rio de Janeiro, v. 4, n. 1, p. 1-17, OutMar 2015. ISSN 1984-0071.

PRIMO, L. et al. Poligonopolis: Prototype of accessible and gamified learning object to teach Geometry. XI Latin American Conference on Learning Objects and Technology (LACLO). San Carlos, Costa Rica: IEEE. 2016. p. 1-9.

QUEVEDO, S. R. P. O Enigma de Gaspar. Objeto de Aprendizagem. Disponível em:
<https://goo.gl/7ICWU3>. Acesso em: 2016.

SOMBRIO, G. S.; SCHIMMELPFENG, L. E.; ULBRICHT, V. R. The production of a gamified Learning Object accessible to people with visual or hearing disabilities for teaching Geometry. 2016 XI Latin American Conference on Learning Objects and Technology (LACLO). San Carlo, Costa Rica: IEEE. 2016. p. 1-10.

ULBRICHT, V.; VANZIN, T.; VILLAROUCO, V. Ambiente Virtual de Aprendizagem Inclusivo. Florianópolis: Pandion, 2011. 352 p.

VANZIN, T.; QUEVEDO, S. R. P. O conto como narrativa para aprendizagem. In: ULBRICHT, V. R.; VANZIN, T.; PONCHMAN, S. R. Conceitos e práticas em ambiente virtual de aprendizagem inclusivo. ${ }^{a}$. ed. São Paulo: Pimenta Cultural, 2014. p. 1-26.

WAKI, F. Os heróis gregos e anglo-saxões ou as transformações de um paradigma. Dissertação. Campinas: Universidade Estadual de Campinas, 2015.

WILSON, C. et al. Alfabetização midiática e informacional: currículo para formação de professores. Brasília: UNESCO, UFMT, 2013. 194 p.

WORLD WIDE WEB CONSORTIUM. Introduction to Web Accessibility, 2005. Disponível em: <http://www.w3.org/WAI/intro/accessibility.php>. Acesso em: 13 nov. 2015.

. Web Content Accessibility Guidelines

(WCAG) 2.0, 2014. Disponivel em: <http://traducoes.w3c.br/TR/WCAG/>. Acesso em: 13 nov. 2015.

\section{Agradecimentos}

À CAPES, pela concessão de bolsa para a doutoranda Lane Primo.
Realização:

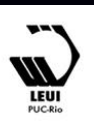

